\title{
Preparation and application of ionic liquid-coated fused-silica capillary fibers for solid-phase microextraction
}

\author{
Kuan-Pin Huang, Guan-Ren Wang, Bao-Yu Huang, Chuen-Ying Liu* \\ Department of Chemistry, National Taiwan University, 1, Sec. 4, Roosevelt Road, Taipei 10617, Taiwan
}

\section{A R T I C L E I N F O}

\section{Article history:}

Received 16 February 2009

Received in revised form 24 April 2009

Accepted 28 April 2009

Available online 3 May 2009

\section{Keywords:}

Ionic liquid

Etching

Solid-phase microextraction

Gas chromatography

\begin{abstract}
A B S T R A C T
A simple and cost effective solid-phase microextraction device has been developed. Fused-silica capillaries were etched with ammonium hydrogen difluoride prior to coating with an ionic liquid. For comparison, both a bare fused-silica capillary and one pretreated with a Nafion membrane were coated with the ionic liquid. All three coated capillaries were employed for the head space microextraction of polycyclic aromatic hydrocarbons (PAHs) which were then separated with an established GC system. Efforts to optimize the extraction process indicated that the etched fiber displayed the most efficient extraction, giving not only highly reproducible extraction results but also greater extraction efficiency. The Nafion membranesupported fiber was inferior to the etched fiber, while the untreated fused-silica had the lowest extraction efficiency. The Nafion membrane contains negatively charged sulfonate groups, and the increase in ionic liquid binding was due to electrostatic attractive forces. However, due to the hydrophobic interactions of the PAHs with the polymer matrix in the Nafion membrane, a more complex adsorption/desorption mechanism might reduce the efficiency. The established method was successfully applied for the analysis of PAHs released from burning of mosquito coil incense.
\end{abstract}

(c) 2009 Elsevier B.V. All rights reserved.

\section{Introduction}

Solid-phase microextraction (SPME) introduced by Arthur and Pawliszyn [1] in the early 1990s, provides many advantages over conventional sample preparation methods by integration of the extraction, concentration and introduction of the sample into a single step. Presently, commercial fibers are available with several different coatings, but use of these fibers is limited due to the instabilities of the coating at high temperatures or in the presence of certain organic solvents. Additionally, lot-to-lot variations of the fibers often result in relatively poor extraction reproducibility. The development of new SPME sorbents and techniques of fiber preparation has been of increasing interest in recent years [2-4]. Fiber coating procedures recently reviewed by Dietz et al. [5], include sol-gel technology, electrochemical methods, and physical deposition. The development of a highly porous SPME fiber coating based on poly(ethylene glycol)-modified ormosils synthesized by sol-gel technology was reported by da Costa Silva and Augusto [6]. An ultrathin phenyl-functionalized SPME fiber coating prepared by sol-gel deposition has been developed by Azenha et al. [7]. Recently, Farhadi et al. [8] prepared novel titania sol-gel coated anodized aluminum fibers for SPME of aromatic hydrocarbons from water

\footnotetext{
* Corresponding author. Tel.: +8862 33661645; fax: +886223638543.

E-mail address: cyliu@ntu.edu.tw (C.-Y. Liu).
}

samples. Turiel et al. [9] proposed the preparation of molecularly imprinted polymeric fibers for SPME. The imprinted fibers showed excellent performance in terms of selectivity and affinity for triazines extracted from environmental and food samples.

Ionic liquids (ILs) have unique properties that are useful in extraction processes: organic species are highly soluble in ILs, while ILs and water are immiscible [10-12]. They can also be physically adsorbed onto SPME fibers due to their high viscosities and negligible vapor pressure. Liu et al. [13] first reported the use of a drop of 1-methyl-3-octylimidazolium hexafluorophosphate $\left(\mathrm{OMIM}-\mathrm{PF}_{6}\right)$ suspended on the tip of a microsyringe for extracting analytes, followed by liquid chromatographic determination of it. Nafion is a perfluorinated polymer with side chains terminating in sulfonic acid. Because of its high ionic conductivity, mechanical strength, chemical stability and low water swelling at operating conditions, it is often used as the proton exchange membrane in fuel cells $[14,15]$. Recently, Hsieh et al. [16] reported that a Nafion membrane could, through electrostatic interactions, increase the amount of IL coating on fused-silica-based SPME fibers. The uniform shape of the 1-methyl-3-octylimidazolium trifluoromethanesulfonate (OMIM-TfO) coating was due to the precoated Nafion membrane.

An alternative technique is single drop microextraction. Yang et al. [17] developed a cataluminescence sensor by coupling ionic liquids-based head space SPME technologies for the ex vivo quantification of human plasma acetone levels associated with diabetic disease. Zhao et al. [18] develop adsorbent coatings based 
on polymeric ionic liquids. While numerous studies have examined the use of ionic liquids in sample preparation [12,19-22], research on the use of ILs in SPME coating, has been limited [16,23,24].

Etched fused-silica capillaries have been used to increase the phase ratio of the bonded material for open tubular capillary electrochromatography [25,26]. Etched bare fused-silica capillaries have also been used to increase the number of silanol groups for the online preconcentration of amino acids in capillary electrophoresis [27]. Because the column is essential to a separation system, much attention has been focused on column technology $[28,29]$. The fiber of the SPME device is just like the column used in traditional separation methods.

In this work, an inexpensive plastic syringe was used as a simple and cost effective SPME device. In order to enhance the amount of coated material, etched fused-silica capillaries were employed for the ionic liquid coating. For comparison of the extraction efficiencies, both a Nafion membrane precoated fused-silica capillary and an untreated fused-silica capillary coated with the ionic liquid were used to extract polycyclic aromatic hydrocarbons (PAHs), which served as model compounds. To determine the stability and the usefulness in a complex matrix, the established method was also applied for the analysis of PAHs released from the burning of mosquito coil incense.

\section{Experimental}

\subsection{Chemicals and materials}

Purified water $(18 \mathrm{M} \Omega \mathrm{cm}$ ) from a Milli-Q water purification system (Millipore, Bedford, MA, USA) was used to prepare all solutions. The following materials were obtained from the indicated sources: ammonium hydrogen difluoride (Strem, Newburyport, MA, USA); biphenyl, dibenzofuran, 1-methylnaphthalene, 2-methylnaphthalene, and naphthalene (Merck, Darmstadt, Germany); ethyl acetate, dichloromethane and methanol (Mallinckrodt, Saint Louis, MO, USA); sodium hydroxide and hydrochloric acid (Riedel-deHaën, Seelze, Germany); acenaphthene, acenaphthylene, fluorene and diphenyl methane (TCI, Tokyo, Japan); azulene, 1-butyl-3-methylimidazolium hexafluorophosphate (BMIM$\mathrm{PF}_{6}$ ) and $\mathrm{OMIM}_{-} \mathrm{PF}_{6}$ (Acros, Geel, Belgium); Nafion 117 (5\% in a mixture of lower aliphatic alcohols and water) (Fluka, Ronkonkoma, NY, USA). Stock solutions of PAHs were prepared in methanol. Mosquito coil incense was purchased from Blood Protection Company (Pulau Pinang, Malaysia).

\subsection{Apparatus}

A Shimadzu model 17A gas chromatograph (Kyoto, Japan) equipped with a capillary column splitless-injection system and an FID system was used for the analyses. Nitrogen was used as the carrier gas. The chromatograms were recorded and processed with Peak-ABC (Taipei, Taiwan) run by a Windows XP operating system. The optical microscope coupled with InterVideo WinDVR3 software was a product of Golden State (San Leandro, CA, USA). Scanning electron microscope (SEM) experiments were performed on a Hitachi S-2400 (Tokyo, Japan). For comparison, a SPME holder with a $7-\mu \mathrm{m}$ polydimethylsiloxane (PDMS) fiber supplied by Supelco (Bellefonte, PA, USA) was also used for SPME analysis. The mosquito coil incense was burned in a rod shape burning chamber (height: $18 \mathrm{~cm}$; radius: $7.5 \mathrm{~cm}$ ).

The fused-silica capillary $(10 \mathrm{~m} \times 250 \mu \mathrm{m}$ i.d. $)$ was obtained from Polymicro (Phoenix, AZ, USA). The GC separation column was prepared according to the procedures published previously [30]. Briefly, a solution of equal amount of 1-benzyl3-methylimidazolium trifluromethanesulfonate (BeMIM-TfO) (1\%, $\mathrm{w} / \mathrm{v})$ and polycatenar oxazoline copper(II) complex $\left[\mathrm{Cu}\left(\mathrm{S}-\mathrm{C}_{12}\right)_{2}\right]$

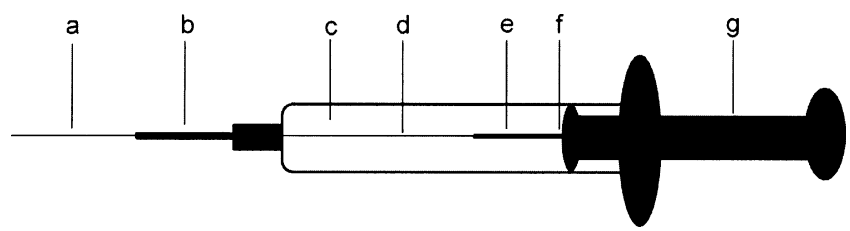

Fig. 1. Schematic diagram of the home-made SPME device: (a) IL-coated fiber; (b) stainless steel needle; (c) plastic syringe body; (d) fused-silica capillary; (e) polyimide-coated fused-silica fiber; (f) polyacrylate adhesive; (g) plunger.

$(1 \%, w / v)$ in dichloromethane was introduced into the column under constant pressure of $0.101 \mathrm{MPa}$. The resultant product was then heated at $40^{\circ} \mathrm{C}$ for $24 \mathrm{~h}$. The coated column was flushed with dry nitrogen for $1 \mathrm{~h}$, and then conditioned from 30 to $120^{\circ} \mathrm{C}$ at an incremental rate of $1^{\circ} \mathrm{C} \mathrm{min}^{-1}$. After conditioning, the coated capillary was ready for use. The carrier gas was nitrogen.

\subsection{SPME device}

The SPME device was constructed from a $3 \mathrm{~mL}$ plastic syringe as shown in Fig. 1. A fused-silica capillary $(9 \mathrm{~cm} \times 50 \mu \mathrm{m}$ i.d. $)$ sealed at both ends (or fused-silica rods) was used as the SPME fiber. Prior to coating with the ionic liquid, a portion of the outer polyimide layer was removed using a microflame torch $(7 \mathrm{~cm}$ of total length). The naked fused-silica capillary was washed with water and acetone sequentially, and then it was dried at $110^{\circ} \mathrm{C}$ for $30 \mathrm{~min}$. The end of the capillary that retained the polyimide coating was pierced into the rubber end of the plunger and was fixed with polyacrylate adhesive (Fig. 1f) to the plunger of a plastic syringe. The clean naked end of the capillary was carefully inserted into the stainless steel needle $(635 \mu \mathrm{m}$ o.d., $318 \mu \mathrm{m}$ i.d.) as shown in Fig. 1b. The fiber can be extended from the needle or retracted inside the needle as needed.

\subsection{Fiber preparation}

The etching process was completed as reported by Pesek et al. [25] with slight modifications. Naked capillaries were immersed in a $5 \%(\mathrm{w} / \mathrm{v})$ saturated solution of ammonium hydrogen difluoride in methanol for $0.5-1.5 \mathrm{~h}$. The capillaries were removed from the etching solution and then dried at ambient temperature for $30 \mathrm{~min}$, followed by heating at high temperature $\left(250-350^{\circ} \mathrm{C}\right)$. The resultant fibers were immersed into BMIM-PF 6 for $3 \mathrm{~min}$ and dried in the air for $10 \mathrm{~min}$. The product was ready for use.

Ionic liquid-coating for the Nafion precoated capillary fibers was performed in a similar manner as for the etched capillary fiber.

\subsection{Sample analysis}

The sampling was carried out using the head space (HS) mode in a $20 \mathrm{~mL}$ sample vial containing $2 \mathrm{~mL}$ of PAH solutions $(500 \mu \mathrm{g}$ $\mathrm{PAH} \mathrm{mL} \mathrm{m}^{-1}$ in methanol). The extraction time was $30 \mathrm{~min}$. The analyte adsorbed onto the fiber was desorbed directly into the GC injector port. The duration for desorption was $5 \mathrm{~min}$ at $220^{\circ} \mathrm{C}$. The separation was carried out with the following temperature programming: $100^{\circ} \mathrm{C}(3 \mathrm{~min}), 3^{\circ} \mathrm{C} \mathrm{min}^{-1}$ to $150^{\circ} \mathrm{C}(1 \mathrm{~min})$, then $10^{\circ} \mathrm{C} \mathrm{min}^{-1}$ to $190^{\circ} \mathrm{C}$, with an inlet pressure of $20 \mathrm{kPa}$.

\section{Results and discussion}

\subsection{Preparation of the highly reproducible etched fiber}

To obtain a greater surface area for improved IL coating, we examined factors that affected the etching processes. Using PAHs as model extracts, we evaluated two kinds of IL, BMIM-PF 6 and $\mathrm{OMIM}_{-} \mathrm{PF}_{6}$. 


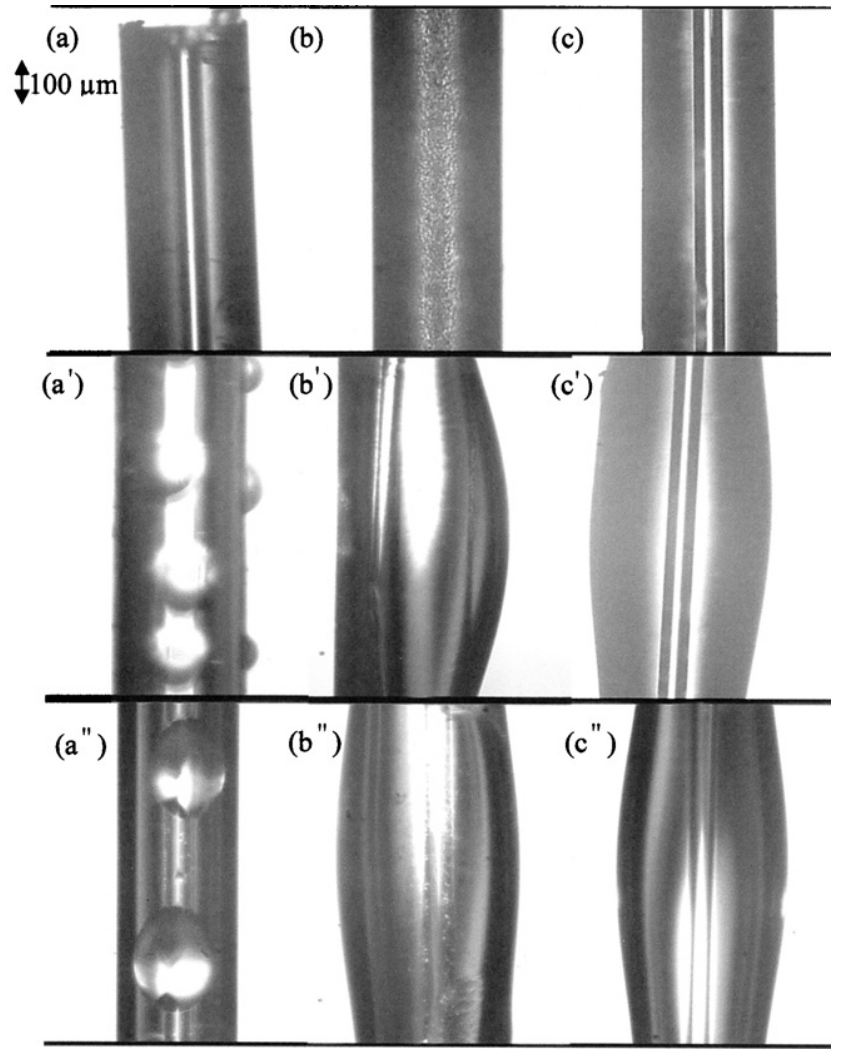

Fig. 2. Optical micrographs of the home-made SPME fibers: (a) bare fused-silica fiber, (b) fused-silica fiber after immersion in the etching solution for $30 \mathrm{~min}$ then heating at $250^{\circ} \mathrm{C}$ for $1 \mathrm{~h}$, and (c) Nafion coated fused-silica fiber. Panels $\left(\mathrm{a}^{\prime}\right)-\left(\mathrm{c}^{\prime}\right)$ show the fibers corresponding to (a)-(c) after BMIM-PF 6 coating, while panels $\left(a^{\prime \prime}\right)-\left(c^{\prime \prime}\right)$ correspond to fiber after OMIM-PF 6 coating.

\subsubsection{Immersion time}

Fig. 2a shows the morphology of the bare fused-silica. After immersion in the etching solution for $30 \mathrm{~min}$, a distinctly rough surface was evident (Fig. 2b). The micrographs indicated that there was a greater amount of the IL BMIM-PF 6 adsorbed on the etched fusedsilica (Fig. $2 b^{\prime}$ ) than that on the Nafion membrane precoated fiber (Fig. $2 \mathrm{c}^{\prime}$ ). When OMIM-PF 6 was used instead of BMIM-PF 6 , similar coating patterns occurred (Fig. $2 \mathrm{a}^{\prime \prime}-\mathrm{c}^{\prime \prime}$ ). A comparison with the morphology of the corresponding fibers (Fig. $2 a^{\prime}-c^{\prime}$ vs. Fig. $2 a^{\prime \prime}-c^{\prime \prime}$ )
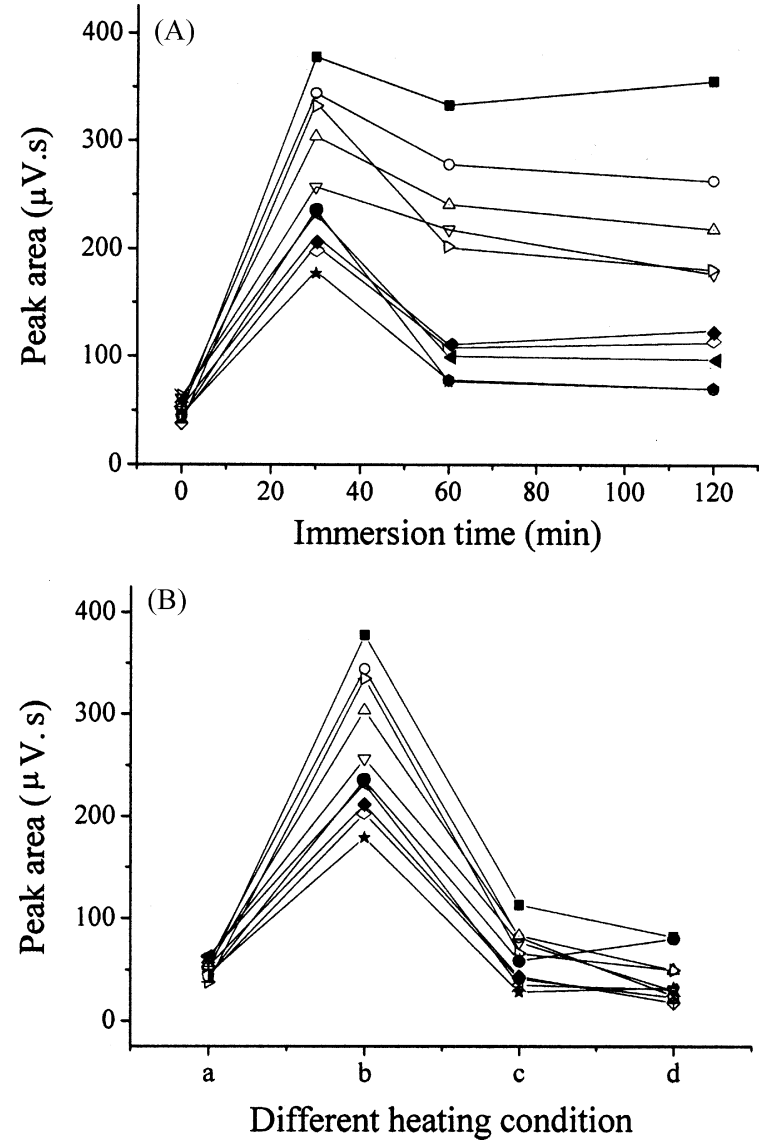

Fig. 3. Influence of etching processes of the fused-silica capillary fibers on the extraction efficiency as evaluated by peak area using the separation conditions outlined in Section 2. (A) Exposure time in the etching solution and (B) heating temperature after etching, where in the $x$-axis (a) bare fused-silica, (b-d) exposure in etching solution for $30 \mathrm{~min}$, then heating at (b) $250^{\circ} \mathrm{C}$ for $1 \mathrm{~h}$, (c) $350^{\circ} \mathrm{C}$ for $1 \mathrm{~h}$, and (d) $350^{\circ} \mathrm{C}$ for $3 \mathrm{~h}$. ( $\left.\mathbf{\square}\right)$ naphthalene, $(\bigcirc)$ 2-methylnaphthalene, $(\triangle)$ 1-methylnaphthalene, $(\nabla)$ azulene, $(\checkmark)$ biphenyl, $(\triangleleft)$ diphenyl methane, $(\triangleright)$ acenaphthene, $(\diamond)$ acenaphthylene, $(\star)$ dibenzofuran, and $(\bullet)$ fluorene.

indicated no significantly different characteristics. Therefore, the less toxic, more ecologically sound IL, BMIM-PF 6 [31] was chosen for further study.

To optimize the etching process of the capillary fiber, we varied the exposure time in the ammonium hydrogen difluoride solu-
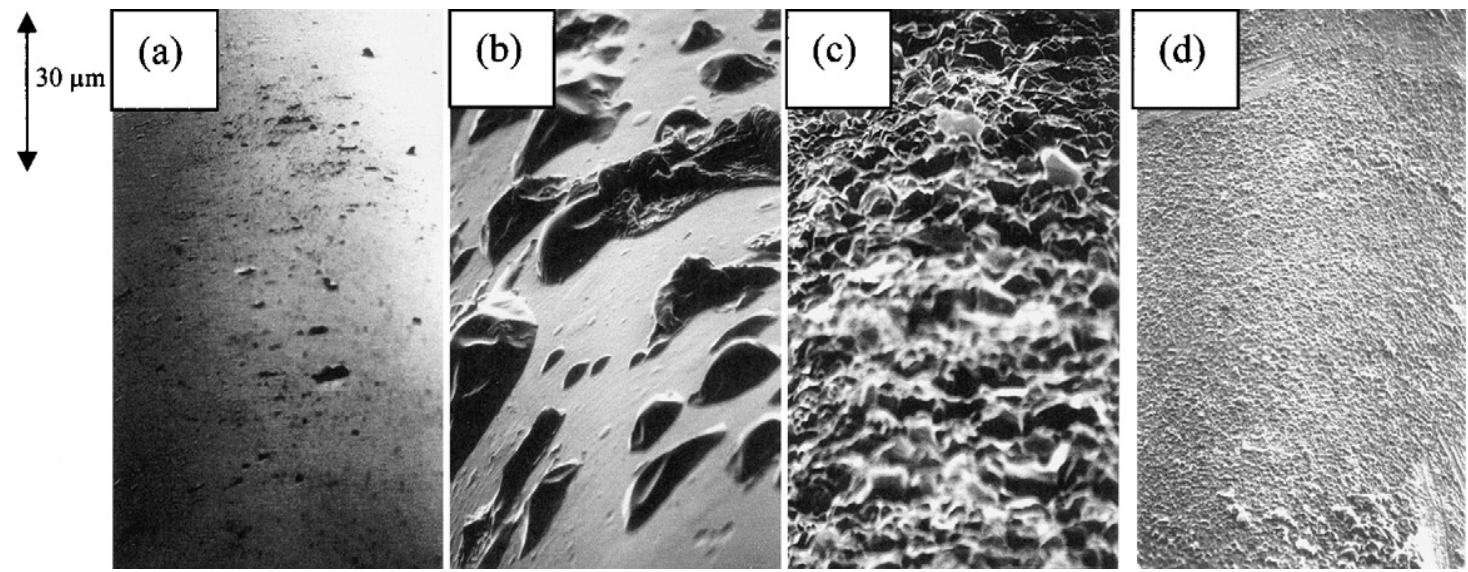

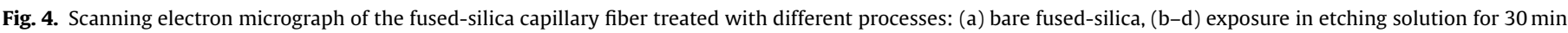
then heating at (b) $250^{\circ} \mathrm{C}$ for $1 \mathrm{~h}$, (c) $350^{\circ} \mathrm{C}$ for $1 \mathrm{~h}$, and (d) $350^{\circ} \mathrm{C}$ for $3 \mathrm{~h}$. 

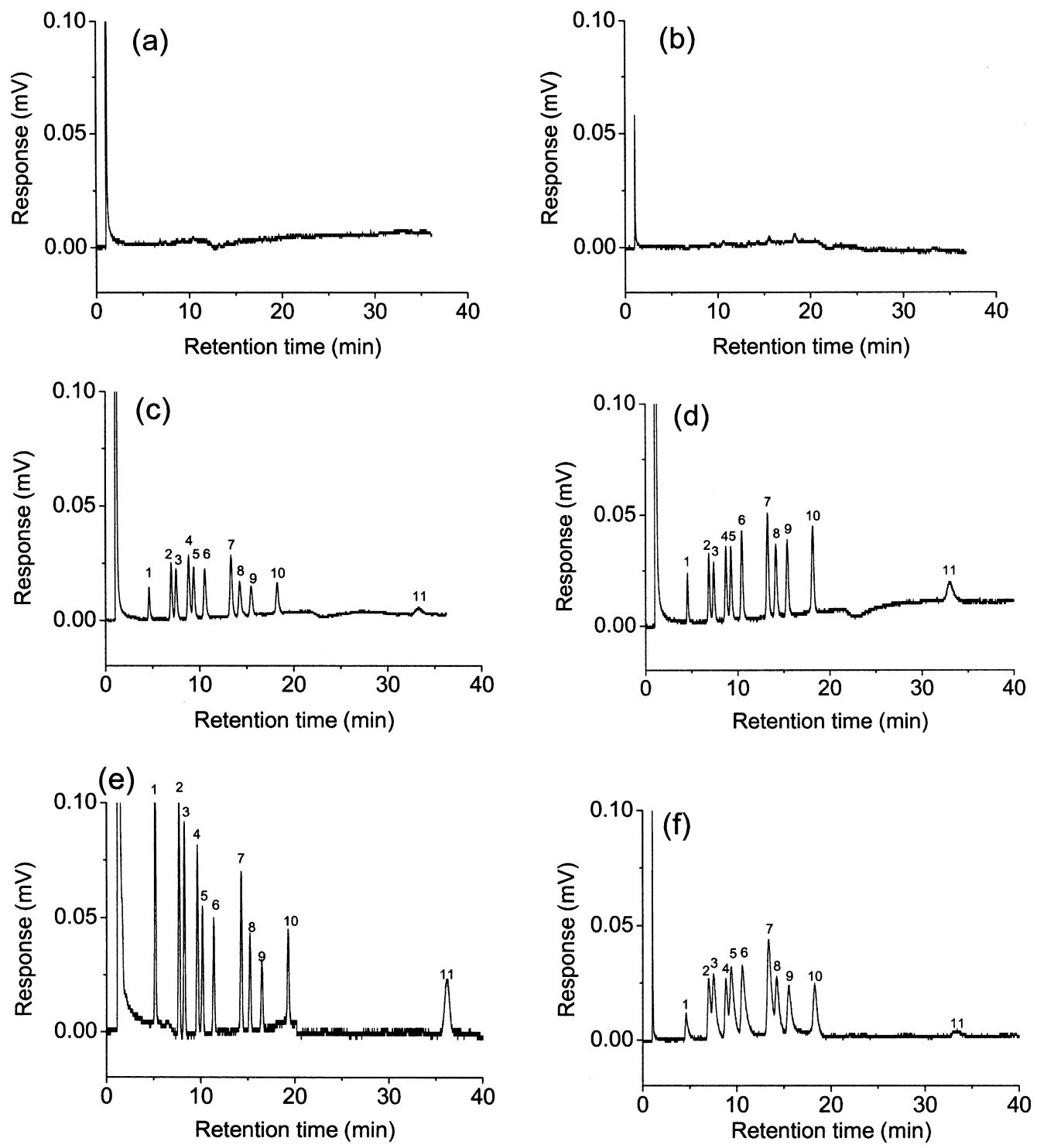

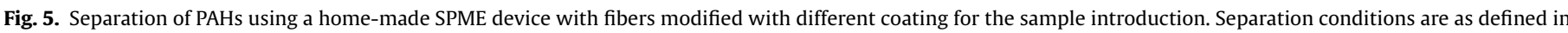

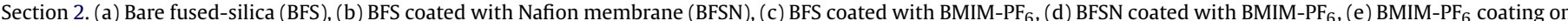

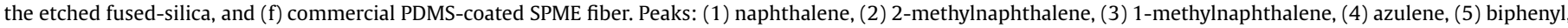
(6) diphenyl methane, (7) acenaphthene, (8) acenaphthylene, (9) dibenzofuran, (10) fluorene, and (11) phenanthrene.

tion from 30 to $120 \mathrm{~min}$ (Fig. 3a). When the immersion time was $30 \mathrm{~min}$, the highest values of peak areas of the tested PAHs were obtained.

\subsubsection{Heating conditions}

After immersion in the etching solution, the fused-silica capillaries were further heated at higher temperature to obtain a stable, rugged surface (Fig. 3b). The highest values of peak areas were obtained when the etching process was conducted at $250^{\circ} \mathrm{C}$ for $1 \mathrm{~h}$.

The surface properties of these materials were further probed by SEM pictures (Fig. 4). Fig. 4a shows the morphology of a bare fusedsilica capillary. In the early stages of the heating process $\left(250^{\circ} \mathrm{C}\right.$ for $1 \mathrm{~h}$ ), the surface was composed of large spikes protruding from the capillary wall (Fig. 4b). Increasing the temperature, less large spikes was seen (Fig. 4c). The surface finally became more uniform after heating at $350{ }^{\circ} \mathrm{C}$ for up to $3 \mathrm{~h}$ (Fig. $4 \mathrm{~d}$ ). Pesek et al. [25] also reported that the heating procedure after the etching step could provide a more uniform surface for the fused-silica capillary.

\subsection{Comparison of the extraction efficiencies of various SPME fibers}

Fig. 5 shows the separation of PAHs using the SPME device for the sample extraction. No sample peak except for methanol could be detected with bare fused-silica (Fig. 5a). Similar results were shown for the Nafion membrane-coated fiber (Fig. 5b). These results indicated that there was no significant interaction between the nonpolar PAH analytes and either the hydrophilic surface of the bare fused-silica or the Nafion membrane-coated fiber.

After IL was coated on each fiber, an obvious improvement in the sample extraction was observed. The extraction efficiency was increased in the order of: bare fused-silica (Fig. 5c) $<$ Nafion membrane coating (Fig. 5d) < etched surface (Fig. 5e). The aromatic system of the imidazolium ring cation in the BMIM-PF 6 offers a $\pi-\pi$ interaction with the PAHs, as reported in the literature [32,33]. The phenomenon was most distinct for the analytes that have a greater vapor pressure.

The extraction efficiency was also carried out with the PDMScoated SPME fiber from Supelco. Lower peak areas were recorded 


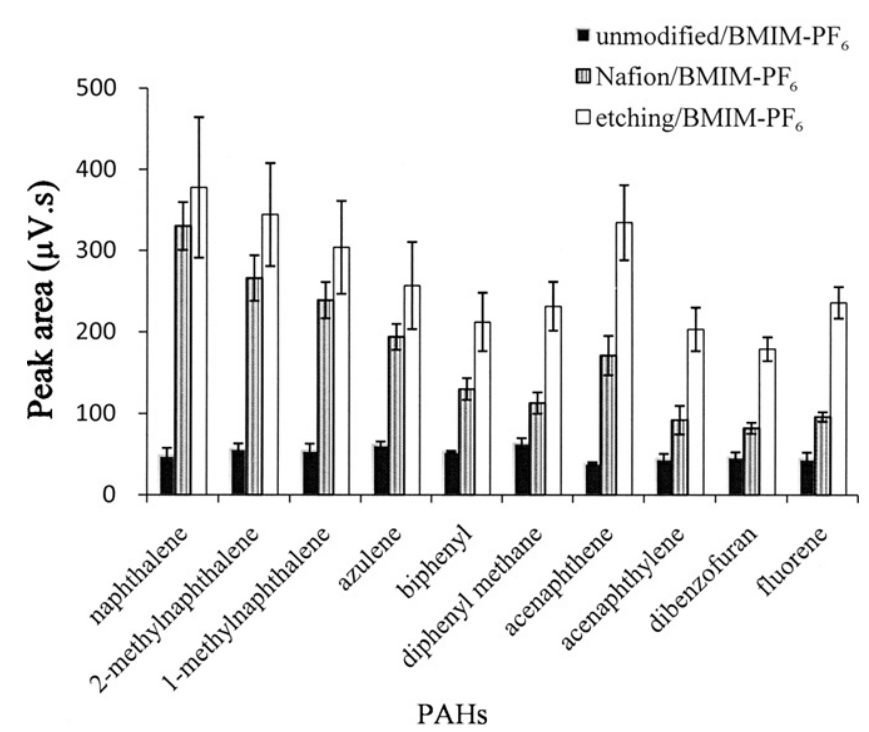

Fig. 6. Comparison of the extraction efficiencies of various IL-coated SPME fibers: (a) BFS, (b) BFSN, and (c) etched surface. Separation condition as in Fig. 5.

(Fig. 5f) by the comparison with those of IL-coated fiber. The phenomena may be attributed to the faster kinetic of mass transfer of analytes from the ILs.

\subsection{Stability and reproducibility of various IL-coated fibers}

We also investigated the reproducibility of the extraction of PAHs by various SPME fibers for the HS-SPME analysis. The peak areas from the fibers precoated with a Nafion membrane were about threefold to fivefold greater than those from the fibers without modification. However, the etched fibers offered the best results among the tested fibers (Fig. 6 and Table 1). In addition, there was a slight difference in the retention time among these fibers. The slower desorption of PAHs from the etched fibers indicates that

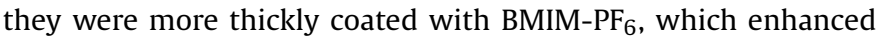
the extraction efficiency for PAHs.

\subsection{Mosquito coil smoke analysis}

Mosquito coil incense was burned in a burning chamber which was capped with the aluminum foil. The smoke was HS extracted then desorbed in the GC injection port. No extraction of the PAHs occurred on the bare fused-silica fiber (Fig. 7a). Better extraction was indicated with the IL-coated fiber (Fig. 7b). For comparison,
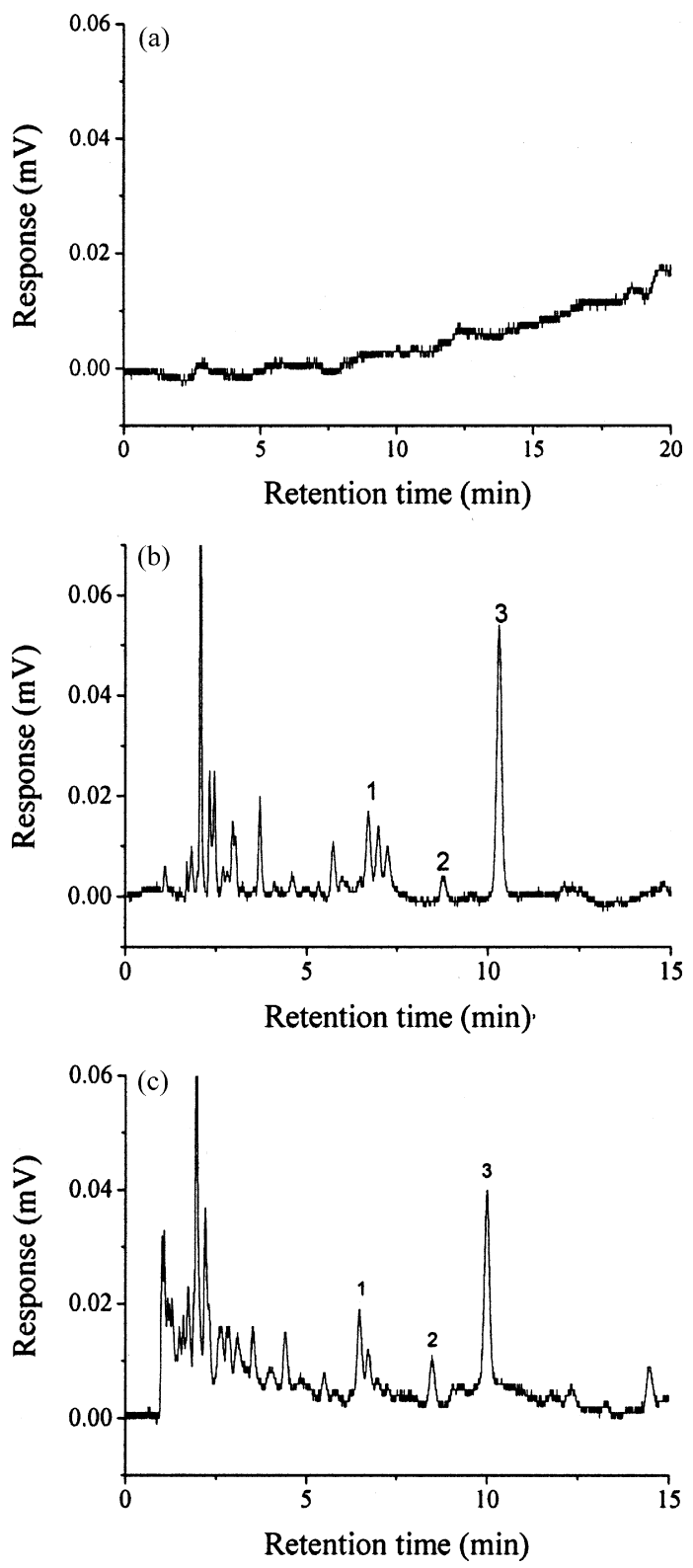

Fig. 7. GC chromatograms for the separation of PAHs released from mosquito coil incense. SPME device: (a) IL-BFS, (b) IL-etched surface, and (c) commercial SPME fiber. Separation conditions as in Fig. 5. Peaks: (1) 2-methylnaphthalene, (2) azulene, and (3) diphenyl methane.

Table 1

Comparison of the extraction efficiencies of various SPME fibers ${ }^{\mathrm{a}}$.

\begin{tabular}{|c|c|c|c|}
\hline \multirow[t]{2}{*}{ Analyte } & \multicolumn{3}{|c|}{ Retention time (R.S.D.) (min); peak area (R.S.D.) ( $\mu V \mathrm{~s})$} \\
\hline & Unmodified $^{\mathrm{b}} / \mathrm{BMIM} \mathrm{PF}_{6}{ }^{\mathrm{b}^{\prime}}$ & Nafion ${ }^{\mathrm{c}} / \mathrm{BMIM}^{-\mathrm{PF}_{6} \mathrm{c}^{\prime}}$ & Etchingd $/ \mathrm{BMIM}^{\mathrm{P}} \mathrm{PF}_{6} \mathrm{~d}^{\prime}$ \\
\hline Naphthalene & $4.6(3.80) ; 50(7.9)$ & $4.8(1.12) ; 330(3.6)$ & $5.2(0.16) ; 380(9.3)$ \\
\hline 2-Methylnaphthalene & $7.1(1.90) ; 60(5.0)$ & $7.2(0.36) ; 270(4.2)$ & $7.7(0.12) ; 340(7.4)$ \\
\hline 1-Methylnaphthalene & $7.6(2.18) ; 50(6.5)$ & $7.8(0.27) ; 240(3.7)$ & $8.3(0.17) ; 300(7.6)$ \\
\hline Azulene & $8.9(3.14) ; 60(3.0)$ & $9.1(0.25) ; 190(3.3)$ & $9.6(0.07) ; 260(8.4)$ \\
\hline Biphenyl & $9.5(2.05) ; 50(2.0)$ & $9.6(0.23) ; 130(4.0)$ & $10.2(0.19) ; 210(6.8)$ \\
\hline Diphenyl methane & $10.6(1.41) ; 60(4.3)$ & $10.8(0.18) ; 110(4.7)$ & $11.4(0.12) ; 230(5.2)$ \\
\hline Acenaphthene & $13.5(1.94) ; 40(1.7)$ & $13.6(0.16) ; 170(5.7)$ & $14.3(0.05) ; 340(5.6)$ \\
\hline Acenaphthylene & $14.5(3.45) ; 40(5.9)$ & $14.6(0.21) ; 90(7.7)$ & $15.2(0.05) ; 200(5.3)$ \\
\hline Dibenzofuran & 15.6 (1.69); $50(5.3)$ & $15.8(0.03) ; 80(3.2)$ & $16.5(0.04) ; 180(3.3)$ \\
\hline Fluorene & $18.3(1.66) ; 40(7.3)$ & $18.5(0.10) ; 100(2.4)$ & 19.3 (0.07); 240 (3.3) \\
\hline
\end{tabular}

\footnotetext{
$\mathrm{b}^{\prime}-\mathrm{d}^{\prime}$ The corresponding fibers after BMIM-PF 6 coating were used for the HS extraction.

a Experimental conditions were as in Fig. 3. The data are the average of three measurements.

b Bare fused-silica fiber.

c Nafion coating on a fused-silica fiber.

d Fiber after $30 \mathrm{~min}$ immersed in the etching solution.
} 


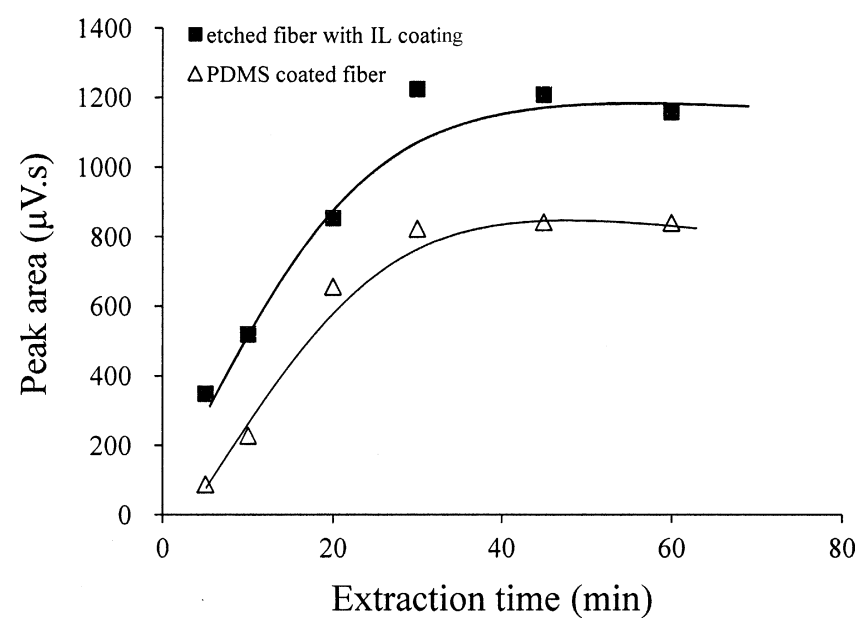

Fig. 8. Comparison the extraction time profiles of diphenyl methane with different fibers. Conditions as in Fig. 7. ( $\mathbf{\square})$ Etched fiber with IL coating; $(\triangle)$ PDMS-coated fiber.

the PDMS SPME fiber from Supelco was also applied in this study. Similar extraction capability was demonstrated with this commercial matrix. Diphenyl methane was the most significant peak(Fig. 7b and c), but the earlier eluting samples (retention time $<5 \mathrm{~min}$ ) were affected by greater noise (Fig. 7c). The unknown components might be benzene, toluene, and other substituted benzene compounds which have greater interaction with the PDMS [34].

The extraction time profiles of diphenyl methane are shown in Fig. 8. The film thickness for etched IL fiber is $30 \mu \mathrm{m}$, and that for PDMS fiber is $7 \mu \mathrm{m}$. In general, the total area of fibers available for adsorption is proportional to the coating volume. For high molecular weight compounds, thin coatings with rapid equilibrium times are expected, increasing coating thickness would adversely affect the time required to reach equilibrium. In this work, similar equilibrium extraction time demonstrated for both etched IL fiber and PDMS fiber. Faster kinetic of mass transfer of analytes in ILs seems to be.

The IL coating is easily refreshed by simply placing the device into the IL after each run. The relative standard deviation of the peak area after 30 min extraction was $8.8 \%$ between coatings, while between different fibers, it was $9.2 \%$. The device can be reused once more unless the fiber is broken.

\section{Conclusions}

The key part of the SPME technique is the fiber coating and it is clear that future advancements in SPME technology would greatly depend on new developments in the areas of sorbent chemistry and coating technology [8]. Relatively few data are currently available on the in-house production of fibers with tailor-made properties for use with SPME [5]. In the present work, a simple and inexpensive home-made device coated with IL was developed for HS-SPME using PAHs as model compounds. Fused-silica capillaries were etched using ammonium hydrogen difluoride prior to applying the IL coating. The preparation of the IL coating on the etched fiber is very easy and convenient. For the experiment we used two ILs, BMIM-PF 6 and OMIM-PF 6 which are stable in the common solvents. The micrographs, however, showed no significant differences in the morphology between the fibers coated with these two ILs. Very good extractions were achieved with both these fibers. The established method was successfully applied for the analysis of PAHs released from burning of a mosquito incense coil. By comparison with the performance of PDMS fiber, faster kinetic of mass transfer of analytes in ILs seems to be. Besides, the dual nature of ILs in the GC separation has been demonstrated in the literatures $[35,36]$. Taking advantage of the mentioned properties, the as-prepared IL-coated fibers could be expected to be widely used in complex matrix sample preparation.

\section{Acknowledgement}

The authors thank the National Science Council of Taiwan for financial support (Grant No. NSC 96-2113-M-002-023-MY3).

\section{References}

[1] C.L. Arthur, J. Pawliszyn, Anal. Chem. 62 (1990) 2145

[2] D. Vuckovic, R. Shirey, Y. Chen, L. Sidisky, C. Aurand, K. Stenerson, J. Pawliszyn, Anal. Chim. Acta 638 (2009) 175.

[3] H. Bagheri, E. Babanezhad, F. Khalilian, Anal. Chim. Acta 634 (2009) 209.

[4] A. Kloskowski, M. Pilarczyk, A. Przyjazny, J. Namieśnik, Crit. Rev. Anal. Chem. 39 (2009) 43.

[5] C. Dietz, J. Sanz, C. Camara, J. Chromatogr. A 1103 (2006) 183.

[6] R.G. da Costa Silva, F. Augusto, J. Chromatogr. A 1072 (2005) 7.

[7] M. Azenha, C. Malheiro, A.F. Silva, J. Chromatogr. A 1069 (2005) 163.

[8] K. Farhadi, R. Tahmasebi, R. Maleki, Talanta 77 (2009) 1285.

[9] E. Turiel, J.L. Tadeo, A. Martin-Esteban, Anal. Chem. 79 (2007) 3099.

[10] V. Pino, J.L. Anderson, J.H. Ayala, V. Gonzalez, A.M. Afonso, J. Chromatogr. A 1182 (2008) 145.

[11] J.H. Wang, D.H. Cheng, X.W. Chen, Z. Du, Z.L. Fang, Anal. Chem. 79 (2007) 620 .

[12] G.A. Baker, S.N. Baker, S. Pandey, F.V. Bright, Analyst 130 (2005) 800

[13] J. Liu, G.B. Jiang, Y.G. Chi, Y.Q. Cai, Q.X. Zhou, J.T. Hu, Anal. Chem. 75 (2003) 5870.

[14] P.P. Kundu, V. Sharma, Y.G. Shul, Crit. Rev. Solid State 32 (2007) 51.

[15] T.M. Thampan, N.H. Jalani, P. Choi, R. Datta, J. Electrochem. Soc. 152 (2005) A316

[16] Y.N. Hsieh, P.C. Huang, I.W. Sun, T.J. Whang, C.Y. Hsu, H.H. Huang, C.H. Kuei, Anal. Chim. Acta 557 (2006) 321

[17] P. Yang, C.W. Lau, X. Liu, J.Z. Lu, Anal. Chem. 79 (2007) 8476.

[18] F. Zhao, Y.J. Meng, J.L. Anderson, J. Chromatogr. A 1208 (2008) 1

[19] Q.X. Zhou, C.L. Ye, Microchim. Acta 162 (2008) 153.

[20] Q.X. Zhou, H.H. Bai, G.H. Xie, J.P. Xiao, J. Chromatogr. A 1177 (2008) 43.

[21] L. Vidal, C.E. Domini, N. Grane, E. Psillakis, A. Canals, Anal. Chim. Acta 592 (2007)

[22] M. Koel, Crit. Rev. Anal. Chem. 35 (2005) 177.

[23] J.F. Liu, N. Li, G.B. Jiang, J.M. Li, J.A. Jonsson, M.J. Wen, J. Chromatogr. A 1066 (2005) 27.

[24] V. Pino, Q.Q. Baltazar, J.L. Anderson, J. Chromatogr. A 1148 (2007) 92.

[25] J.J. Pesek, M.T. Matyska, S. Velpula, J. Chromatogr. A 1126 (2006) 298.

[26] J.J. Pesek, M.T. Matyska, J. Chromatogr. A 736 (1996) 255.

[27] Q.S. Qu, Y. Liu, X.Q. Tang, C.Y. Wang, G.J. Yang, X.Y. Hu, C. Yan, Electrophoresis 27 (2006) 4500.

[28] C.Y. Liu, Electrophoresis 22 (2001) 612.

[29] Y.Z. Yang, R.I. Boysen, M.T. Matyska, J.J. Pesek, M.T.W. Hearn, Anal. Chem. 79 (2007) 4942.

[30] K.P. Huang, T.K. Misra, G.R. Wang, B.Y. Huang, C.Y. Liu, J. Chromatogr. A 1215 (2008) 177.

[31] S. Stolte, S. Abdulkarim, J. Arning, A.K. Blomeyer-Nienstedt, U. Bottin-Weber, M. Matzke, J. Ranke, B. Jastorff, J. Thöming, Green Chem. 10 (2008) 214.

[32] P. Stepnowski, J. Nichthauser, W. Mrozik, B. Buszewski, Anal. Bioanal. Chem. 385 (2006) 1483.

[33] P. Mignon, S. Loverix, P. Geerlings, Chem. Phys. Lett. 401 (2005) 40

[34] I.Y. Eom, A.M. Tugulea, J. Pawliszyn, J. Chromatogr. A 1196 (2008) 3.

[35] D.W. Armstrong, L.F. He, Y.S. Liu, Anal. Chem. 71 (1999) 3873.

[36] J.L. Anderson, D.W. Armstrong, Anal. Chem. 77 (2005) 6453. 